\title{
A Covid-19 e o agravamento das desigualdades na Região Metropolitana do Rio de Janeiro
}

\author{
Covid-19 and the worsening of inequalities \\ in the Metropolitan Region of Rio de Janeiro
}

Georges Flexor [I]

Robson Dias da Silva [II]

Adrianno Oliveira Rodrigues [III]

\section{Resumo}

Este artigo trata dos impactos da Covid-19 na renda da população da Região Metropolitana do Rio de Janeiro. A análise dos dados da aplicação de um web-survey confirma as hipóteses apontadas na literatura internacional no que diz respeito ao papel da pandemia de Covid-19 no agravamento de desigualdades sociais preexistentes. Além disso, o artigo informa que as desigualdades ocorrem nas áreas periféricas da metrópole fluminense, nas quais os impactos negativos são comparativamente muito superiores aos de outras áreas. A segurança econômica tornou-se mais desigual adiante da pandemia de Covid-19, quando comparados o lugar de moradia, a cor e o gênero dos habitantes.

Palavras-chave: desigualdades; Covid-19; Rio de Janeiro; insegurança econômica.

\begin{abstract}
This article deals with the impacts of Covid-19 on the income of the population living in the Metropolitan Region of Rio de Janeiro. The analysis of data from a web survey confirms the hypotheses pointed out in the international literature regarding the role of the Covid-19 pandemic in the worsening of pre-existing social inequalities. Also, the article shows that the inequalities occur in the peripheral areas of the Rio de Janeiro Metropolis, where the negative impacts are much greater compared to other areas. Economic security has become more unequal in the Covid-19 pandemic when we compare the inhabitants' dwelling place, skin color, and gender.
\end{abstract}

Keywords: inequalities; Covid-19; Rio de Janeiro; economic insecurity. 
Além de desencadear uma crise sanitária sem precedentes, a pandemia provocada pela Covid-19 está impactando a economia brasileira de forma dramática. Segundo a Pesquisa Nacional por Amostra de Domicílio (Pnad-Covid19), realizada especialmente para medir os impactos do novo coronavírus, $77,8 \%$ das empresas em funcionamento no Brasil reportaram que a Covid-19 impactou negativamente esse ramo da economia - 13,5\% delas reduziram o número de funcionários, e, destas, 10,5\% indicaram redução de mais de $50 \%$ de empregados. Os impactos sobre o mercado de trabalho não foram menos agudos. A taxa de desocupação, que era de 10,5\% no início de maio de 2020, alcançou 13,3\% no início de agosto. Em paralelo ao aumento da taxa de desocupação de 2,8 pontos percentuais em três meses, a piora no mercado de trabalho traduziu-se em perdas de rendimentos. A Pnad-Covid19 informa que, em julho de 2020, 30,7\% das pessoas ocupadas tiveram rendimentos menores do que os recebidos normalmente. Esses dados também sinalizam que as pessoas pretas ou pardas e aquelas com menores níveis de escolaridade foram as mais negativamente atingidas pelos impactos econômicos da Covid-19.

Este artigo evidencia que as desigualdades sociais, elevadas pela pandemia, geraram impactos negativos elevados nas áreas periféricas, a exemplo da Região Metropolitana do Rio de Janeiro. Baseado nos resultados da aplicação de um web-survey no início do mês de abril de 2020, o artigo é uma contribuição original que se soma aos esforços de outros pesquisadores que buscam melhor entender as consequências socioespaciais da pandemia na segunda maior metrópole do País (Britto et al., 2020). Antes de apresentar a análise dos dados do survey, o artigo aborda alguns temas levantados pela literatura internacional no tocante à relação entre Covid-19 e desigualdades socioeconômicas. Também destaca duas características importantes do contexto socioespacial metropolitano: a desigualdade espacial da distribuição dos rendimentos e a crise do mercado de trabalho.

\section{Covid-19 e os riscos de acentuação das desigualdades no Brasil}

A pandemia provocada pelo novo coronavírus tem se apresentado como o maior desafio enfrentado pela humanidade desde o fim da II Grande Guerra. Tida como um grande choque sistêmico global, a Covid-19 tem alcançado números impressionantes em diversas frentes, desde mortos e infectados, passando por crianças e jovens fora das salas de aula, firmas falidas e pessoas desempregadas. 0 grande lockdown (termo cunhado pelo Fundo Monetário Internacional - FMI, para designar o conjunto de medidas de paralisação da economia por conta do afastamento social) mostra-se um desafio de magnitude inédita, considerando que a crise econômica nele experimentada não tem origem em fundamentos macroeconômicos como observado em crises anteriores, mas sim em questões de ordem sanitária.

Os impactos econômicos e sociais já se mostram profundos, e os esforços para recuperação serão de tamanho inédito, demandando ainda algum tempo para alcançar os indicadores pré-crise. O FMI (2020) estima que a economia mundial encolherá em torno de 5,1\% 
em 2020, ante o crescimento de 3,0\% em 2019. Esses números resultam das medidas de isolamento e distanciamento social postas em prática por quase todos os países na contenção da pandemia.

Ainda que os efeitos sejam sentidos em várias partes do mundo, já se faz claro que os países mais pobres e aqueles classificados como em desenvolvimento são os que mais sofrem com os efeitos da crise, muito em razão de fragilidades estruturais presentes em sua oferta de bens públicos e estrutura produtiva, como também por limitações de ordem fiscal e financeira. O Brasil, por exemplo, deve ter queda do seu produto interno bruto de $8,1 \%$ em 2020, a o passo que o número de desempregados pode ultrapassar, segundo estimativas, os 20 milhões (Pnad-Covid19).

Um dos efeitos esperados da pandemia é o recrudescimento das desigualdades em escala global, reafirmando e fortalecendo fenômeno que já vinha se destacando no debate internacional. À época dos rumores acerca da atual pandemia, detinha alguma força a ideia de que todos estavam no mesmo barco, ou seja, que essa crise alcançaria igualmente todas as classes sociais, nas diversas partes do mundo. Talvez por isso, no começo da Covid-19, tenha ganhado algum eco o tipo de discurso de que o vírus nos igualaria, pouco importando a classe social de pertencimento.

Muito rapidamente, contudo, o inverso mostrou-se, e a Covid-19 passou a ser vista como uma força em direção ao reforço das desigualdades preexistentes, ao atingir estratos sociais mais pobres ou grupos por suas razões mais vulneráveis. De um lado, verifica-se uma propensão muito mais acentuada para a ocorrência de casos graves e óbitos entre negros, indígenas e idosos. De outro lado, mulheres e crianças são duramente atingidas pelas consequências da pandemia, tais como a sobrecarga de trabalho e a maior exposição à violência no ambiente doméstico, a privação do aprendizado e do convívio por conta do fechamento das escolas, os riscos de comprometimento da saúde psíquica, etc.

Nesse sentido, destaca-se que, para Milanovic (2016), são duas as forças principais que agem reduzindo a desigualdade. As "forças benignas" englobariam todas as ações políticas e econômicas cujo objetivo principal seria a redução da desigualdade; dentre estas se destacam as transferências governamentais, investimento em educação e progressividade na taxação de renda. E as "forças malignas" seriam aquelas sobre as quais não haveria controle, tais como guerras, epidemias e catástrofes naturais. Elas seriam malignas porque, não obstante poderem incorrer em redução da desigualdade, também poderiam reduzir a riqueza econômica de um país.

No entanto, a ideia proposta por Milanovic (ibid.) acerca dos resultados esperados das "forças malignas" sobre a desigualdade parece ter validade apenas parcial. Apesar de estar correta em relação à redução de renda para todos, sua proposição desconsidera que essa perda é mais acentuada para alguns estratos que têm somente no trabalho (salários) sua fonte de renda e patrimônio.

O Brasil, país de dimensões continentais, é historicamente reconhecido como um dos mais desiguais dentre aqueles que formam o grupo dos em desenvolvimento. As desigualdades apresentam-se na economia brasileira em diferentes escalas (regional, gênero, cor, funcional) e são historicamente apontadas como a matriz dos principais problemas econômicos e sociais do País. Piketty 
(2014) destaca que o Brasil é o país onde o 1\% mais rico detém a maior concentração de riqueza. Em 2015, ano mais recente com dados sobre o Brasil, $27,8 \%$ da renda nacional estava sob posse do $1 \%$ mais rico, uma porcentagem maior, até mesmo, do que a detida pelo $1 \%$ mais rico do Oriente Médio. A pesquisa mostrou, ainda, que os $10 \%$ mais ricos do Brasil detinham $55 \%$ da renda, ficando atrás somente do Oriente Médio, com $61 \%$. No caso da Europa, $37 \%$ da renda nacional pertencem aos $10 \%$ mais ricos.

Por isso, o temor de que, com a pandemia, o País tenha acentuadas suas desigualdades e sofra retrocesso maior não é descabido e se torna objeto central de preocupação entre muitos acadêmicos e gestores públicos. A literatura internacional e nacional sobre os riscos do aumento das desigualdades por conta da Covid-19 tem destacado quais seriam os principais canais de transmissão que reforçariam a piora do quadro da distribuição de renda em médio e longo prazos.

Esses estudos (Blundell et al., 2020; Neidhöfer, 2020; Nyqvist et al., 2020) têm por base dados e cenários apurados em outras pandemias (ebola, na África, e H1N1, na Ásia) e o estudo em regiões do Reino Unido, já no quadro da atual pandemia. Os resultados apresentados indicam um importante caminho para se pensar a realidade brasileira, notadamente porque os canais de transmissão apontados são todos eles também observados nesse momento como efeitos da Covid-19 sobre a economia e o cotidiano do País. Esses canais teriam efeitos imediatos, mas especialmente intergeracional, afetando a qualidade de vida e as condições econômicas dos estratos sociais de rendas baixas.
O primeiro canal seria o educacional. Por conta das políticas de isolamento ou afastamento social, foi necessário o fechamento de escolas e demais instituições de ensino, um grande quantitativo de crianças e jovens encontra-se fora de sala de aula, algumas sem nenhum tipo de atividade educativa formal. Dados da ONU indicam que 189 países apresentaram algum grau de fechamento de instituições de ensino, o que levou a aproximadamente 1,5 bilhão de estudantes fora dos espaços escolares.

As crianças e os jovens dos estratos sociais mais vulneráveis encontram-se em clara desvantagem em relação àqueles de grupos sociais mais abastados. 0 homeschooling traz um conjunto de demandas físicas e culturais nem sempre encontradas nas residências mais pobres, tais como acesso regular à internet, computadores e demais equipamentos de informática, além do apoio e do suporte familiar e profissional mais individualizados. 0 grande risco esperado desse cenário é a ampliação do intervalo de qualificação e aquisição de conhecimento entre os mais ricos e mais pobres, podendo condenar toda uma geração a postos de trabalho menos qualificados no futuro. Dado ser a educação o principal determinante para a ocupação de postos de trabalho mais qualificados, seguros e de maior remuneração, os efeitos da pandemia sobre a escolarização dos mais pobres tem grande potencial de reforço às desigualdades já existentes, notadamente em países com grande déficit educacional, como o Brasil.

A saúde é apontada como o segundo canal de transmissão de reforço sobre as desigualdades junto às pandemias. Concentrando-se os números de infectados e mortos entre os mais pobres, haveria maior desestabilização 
familiar e perda de renda entre estes. Ademais, os efeitos colaterais ainda pouco conhecidos da Covid-19 poderia incorrer em maior número de incapacitados ou limitados ao trabalho entre as classes mais populares, gerando efeitos sobre as condições sociais de todo o grupo familiar. Tal como em crises sanitárias pretéritas, o risco de orfandade é maior também entre os mais pobres, fazendo com que crianças e jovens possam ter que interromper estudos e entrar precocemente no mercado de trabalho, comumente em ocupações que exigem baixa qualificação e oferecem pouca remuneração e segurança.

Por fim, o terceiro canal seria a renda, associada ao mercado de trabalho e ao patrimônio pessoal acumulado. Em uma conjuntura pandêmica, em que medidas de restrição à mobilidade urbana são adotadas, os mercados de trabalho locais são abrupta e rapidamente atingidos. Com a Covid-19, os trabalhadores de maior escolaridade e, por conseguinte, de maior remuneração formam quase que na totalidade o grupo dos que o trabalho de casa se tornou uma opção de fato. Assim, em que pesem perdas relativas à carga de trabalho $e$ emocional empreendidas, estes conseguiram maior estabilidade em termos de ocupação e, principalmente, renda. Os trabalhadores de menor escolaridade foram os mais duramente atingidos pelo grande lockdown, muitos dos quais quase que imediatamente ao anúncio de medidas de isolamento social. Especialmente no mercado de trabalho dos serviços, dependente por sua natureza do ir e vir das cidades, a perda de renda foi quase imediata, notadamente para os trabalhadores em condições mais frágeis, os ocupados em setores informais, paralisados por completo com as medidas de restrição da mobilidade.
Importante assinalar que esses três canais se comunicam e seus efeitos são interativos entre si. Por exemplo, a queda da renda provocada pelo maior desemprego leva à maior insegurança alimentar e à incapacidade de prover as condições materiais necessárias ao ensino escolar remoto, atuando então sobre a educação e a saúde. Através desses canais, grupos mais em desvantagem seriam duramente afetados pela Covid-19, em especial populações que vivem nas periferias urbanas das grandes metrópoles nacionais e áreas rurais com grande déficit de infraestrutura social básica.

A seguir, analisa-se o impacto da pandemia na insegurança econômica na Região Metropolitana do Rio de Janeiro, uma metrópole caracterizada por intensas desigualdades sociais, econômicas e espaciais e que sofreu, mais que qualquer outra grande cidade brasileira, os impactos da crise econômica que assola o País desde o final de 2014.

\section{A Região Metropolitana do Rio de Janeiro - Breve histórico}

Criada em 1974, a Região Metropolitana do Rio de Janeiro (RMRJ) ${ }^{1}$ institucionaliza o espraiamento urbano desde a antiga capital federal em direção à sua periferia imediata, então região reconhecida como "Grande Rio". O período em que a cidade do Rio de Janeiro exerceu o papel de capital federal permitiu que, com a centralização das funções administrativas da União, fosse garantido um fluxo regular e estável de recursos. Mesmo com o baixo dinamismo da economia carioca à época, esses recursos, boa parte dos impostos 
recolhidos, deveriam, por definição legal, ser aplicados nos limites do território do município do Rio de Janeiro, deixando, dessa forma, áreas como a Baixada Fluminense como espaço de dormitório da massa trabalhadora.

0 contexto de criação dessas regiões metropolitanas acompanhou, de certa forma, o processo de urbanização do País e todas as contradições nele existentes. O objetivo embutido na concepção de tais regiões metropolitanas foi o de integrar os municípios que delas faziam parte, facilitando o processo de implementação de políticas comuns a eles. Longe disso, o viés centralizador e autoritário da lei que criou a RMRJ acabou por acirrar os conflitos de competência entre os entes envolvidos no processo. Isso acabou gerando a desarticulação da prestação de serviços básicos de infraestrutura urbana, de transporte e da gestão sustentável dos recursos hídricos. Tal fato acabou conduzindo, segundo a Câmara
Metropolitana do Rio de Janeiro, "a um processo de urbanização da nossa metrópole, gerador de espaços fragmentados, trazendo consigo estrangulamentos de funcionamento e inadequação ambiental" (Câmara Metropolitana, 2016).

A RMRJ foi recentemente redefinida pela lei complementar n. 184/2018, contando atualmente com 22 municípios (Mapa 1): Belford Roxo, Cachoeira de Macacu, Duque de Caxias, Guapimirim, Itaboraí, Itaguaí, Japeri, Magé, Maricá, Mesquita, Nilópolis, Niterói, Nova Iguaçu, Paracambi, Petrópolis, Queimados, Rio Bonito, Rio de Janeiro, Seropédica, São Gonçalo, São João de Meriti e Tanguá (Britto et al., 2020). Estes ocupam uma área de 6,7 milhões de $\mathrm{km}^{2}$, com aproximadamente 12,2 milhões de habitantes, sendo 6.390.290 habitantes do município do Rio de Janeiro (aproximadamente 52\% do total), e um PIB da ordem de R\$405 bilhões.

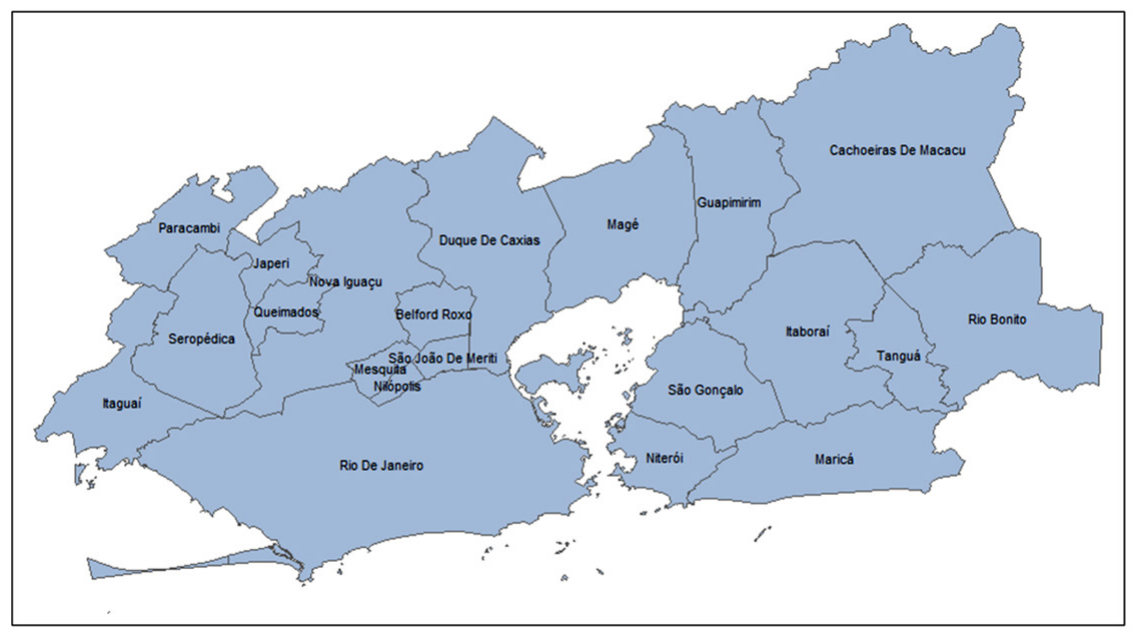

Fonte: elaboração própria com base em dados georreferências do IBGE (disponível em: https://www. ibge.gov.br/geociencias/organizacao-do-territorio/malhas-territoriais/15774-malhas.html?=\&t=o-que-e; acesso em: 7 ago 2020). 
A RMRJ é uma amostra expressiva do quadro de desigualdades sociais, econômicas, infraestruturais e ambientais que se observa na maioria das cidades brasileiras e latino-americanas. Ela apresenta como principal questão a ser enfrentada a redução da forte desigualdade, principalmente na parte denominada Baixada Fluminense ${ }^{2}$ que representa em torno de $30 \%$ da população da região metropolitana e apresenta os piores indicadores sociais da região.

\section{A RMRJ na atualidade: enfrentamentos e desafios}

A acentuada desigualdade que marca a RMRJ possui uma clara expressão territorial. Isso pode ser observado nos dados sobre distribuição da renda contidos no Mapa 2. Vê-se claramente que os bairros da Zona Sul da cidade do Rio de Janeiro e a Barra da Tijuca, áreas de cores verdes, concentram a população de maior renda. Nesses bairros, a renda per capita é muitas vezes superior a 5 salários-mínimos, elevando-se frequentemente a mais de 10 salários-mínimos quanto mais próximas às praias oceânicas, nas quais residem as pessoas mais ricas. Em comparação, à exceção do município de Niterói, onde reside uma importante classe média alta, nas outras áreas da cidade do Rio de Janeiro, as chamadas Zona Oeste (exceto o bairro da Barra da Tijuca, localizado próximo às praias oceânicas) e Zona Norte, e nos demais municípios da RMRJ, a renda per capita é geralmente inferior a 2 salários-mínimos. Em extensas áreas da Baixada Fluminense, da Zona Oeste e de outros municípios situados no recôncavo da baía de Guanabara, a renda per capita pode ser inferior a um salário-mínimo.

Mapa 2 - Renda média per capita em salário-mínimo na Região Metropolitana do Rio de Janeiro - 2016
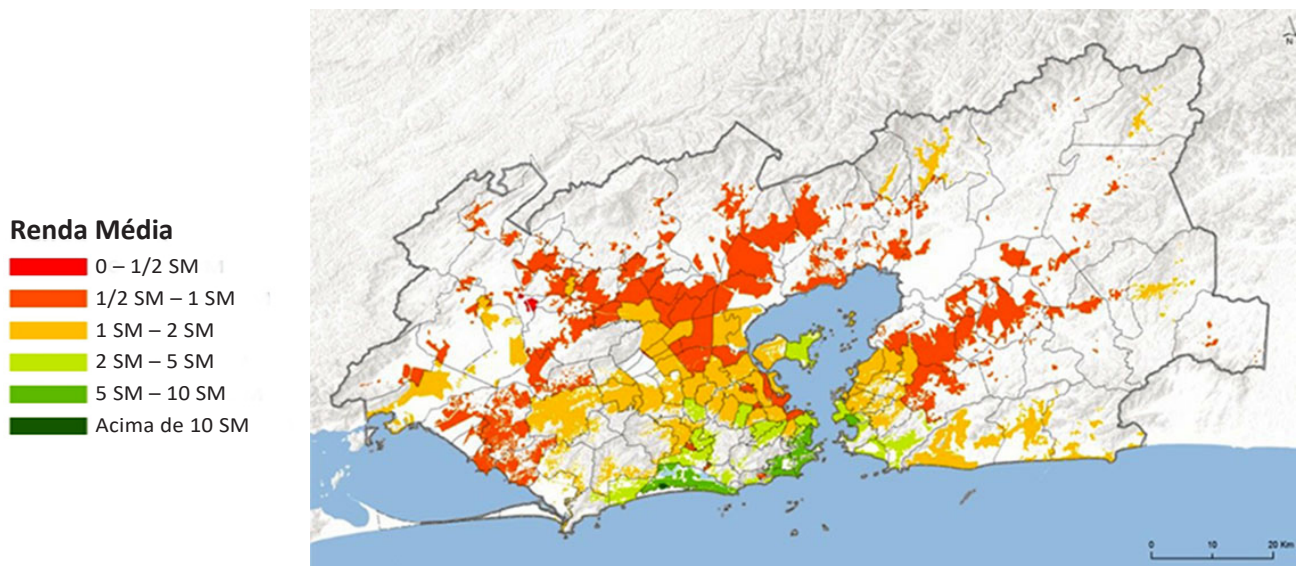

Fonte: Modelar a metrópole (disponível em: https://www.modelarametropole.com.br/wp-content/ uploads/2017/03/06-economia_-renda.jpg; acesso em: 7 ago 2020). 
A desigualdade desnudada pela recente crise sanitária imposta pelo coronavírus é, de certa maneira, um processo histórico já conhecido, que acompanha o crescimento da RMRJ desde sua criação nos anos 1970. Segundo (Osorio et al., 2020), entre 1970 e 2017, o estado do Rio de Janeiro apresentou uma perda de participação no PIB nacional da ordem de $38,8 \%$, a maior perda entre todas as unidades federativas. Nos anos 2000, o crescimento do preço do petróleo, os diversos grandes investimentos relacionados com a exploração dos hidrocarbonetos e a preparação de eventos esportivos de grandes portes, como a Copa do Mundo e os Jogos Olímpicos, favoreceram a economia da RMRJ, resultando numa significativa melhora do mercado de trabalho. Todavia, quando os preços do petróleo iniciaram sua trajetória de queda em 2014, coincidindo com a diminuição da demanda por trabalho oriunda das obras vinculadas aos grandes eventos esportivos no final de 2015, o mercado do trabalho deteriorou-se rapidamente.

A comparação das taxas de desocupação nas principais áreas metropolitanas brasileiras mostra que a crise econômica que assola o País desde 2014 foi mais intensa na RMRJ do que em qualquer outra região. As taxas de desocupação das áreas metropolitanas são informadas no Quadro 1. Pode-se observar que o mercado de trabalho piorou em todos os grandes centros urbanos brasileiros desde janeiro de 2015. Todavia, existem diferenças importantes, e é notável que a piora mais expressiva ocorreu na metrópole fluminense. Em janeiro de 2015, a taxa de desocupação da RMRJ era a menor entre as áreas metropolitanas brasileiras, 3,21 pontos abaixo da média das demais. Cinco anos depois, um mês antes de eclodir a crise sanitária, a taxa de desocupação da RMRJ tinha se tornado a terceira maior entre todas as áreas metropolitanas, sendo superada apenas pelas de Salvador e Recife. Sua taxa de desocupação, de $14,80 \%$, agora era superior em 1,63 pontos à média das demais. Ou seja, enquanto a taxa de desocupação cresceu em média 3,967 pontos nessas áreas metropolitanas, ela aumentou 8,8 pontos na RMRJ. Isso contribuiu para a geração de uma grave crise social.

É, portanto, num cenário de crise econômica e de desigualdades sociais, econômicas e espaciais, que eclodiu a crise sanitária provocada pela pandemia da Covid-19. Será que a pandemia aprofunda as desigualdades sociais, econômicas e espaciais que caracterizam a metrópole fluminense? Uma pessoa morando na periferia, na Baixada Fluminense por exemplo, tem mais chance de sofrer uma diminuição de renda devido aos efeitos da Covid-19 sobre o mercado do trabalho que uma pessoa morando na Zona Sul do município do Rio de Janeiro? E um homem branco que reside na Zona Sul tem muito mais chance de manter sua renda do que uma mulher parda ou preta que habita a Zona Oeste da cidade do Rio de Janeiro? Quais foram as categorias profissionais que mais sofreram perdas de rendimentos com a pandemia?

\section{Os dados}

Em meados de abril de 2020, foi aplicado um survey online (web-based survey) com o objetivo de coletar informações capazes de proporcionar algumas respostas a essas questões. Ainda que esse instrumento tenha restrições que não podem ser minimizadas, os mais proeminentes delas sendo os problemas de representatividade decorrentes dos vieses 
Quadro 1 - Taxa de desocupação nas principais áreas metropolitanas brasileiras 2015-2020

\begin{tabular}{|c|c|c|c|c|c|c|c|c|c|}
\hline & \multicolumn{9}{|c|}{ Região Metropolitana } \\
\hline & $\begin{array}{l}\text { Rio de } \\
\text { Janeiro }\end{array}$ & Fortaleza & Recife & Salvador & $\begin{array}{c}\text { Belo } \\
\text { Horizonte }\end{array}$ & Belém & São Paulo & Curitiba & $\begin{array}{l}\text { Porto } \\
\text { Alegre }\end{array}$ \\
\hline $01 / 2015$ & 6,00 & 7,80 & 7,70 & 14,80 & 9,70 & 13,40 & 8,70 & 5,30 & 6,30 \\
\hline $04 / 2015$ & 6,50 & 8,80 & 7,10 & 16,80 & 9,20 & 12,90 & 9,30 & 5,90 & 6,70 \\
\hline 07/2015 & 7,60 & 9,60 & 10,20 & 17,10 & 9,70 & 11,90 & 9,80 & 5,70 & 7,30 \\
\hline $10 / 2015$ & 7,70 & 9,20 & 11,80 & 14,60 & 10,20 & 11,90 & 10,60 & 5,20 & 7,00 \\
\hline $01 / 2016$ & 9,20 & 11,50 & 13,40 & 18,40 & 13,10 & 13,60 & 12,60 & 8,90 & 8,30 \\
\hline $04 / 2016$ & 10,70 & 11,80 & 14,60 & 19,20 & 13,90 & 14,00 & 12,70 & 8,90 & 10,10 \\
\hline $07 / 2016$ & 11,60 & 14,20 & 16,50 & 19,60 & 14,40 & 15,60 & 14,00 & 9,40 & 10,40 \\
\hline $10 / 2016$ & 13,20 & 12,00 & 15,80 & 19,10 & 13,60 & 13,90 & 13,50 & 8,90 & 9,90 \\
\hline $01 / 2017$ & 14,30 & 14,00 & 18,00 & 18,30 & 15,80 & 15,40 & 15,20 & 11,20 & 10,90 \\
\hline 04/2017 & 15,60 & 13,50 & 19,70 & 19,10 & 16,20 & 14,00 & 14,60 & 10,40 & 10,20 \\
\hline $07 / 2017$ & 14,50 & 11,40 & 20,00 & 18,30 & 16,20 & 14,10 & 14,20 & 10,90 & 9,50 \\
\hline $10 / 2017$ & 15,20 & 10,60 & 18,60 & 16,50 & 13,50 & 12,60 & 14,20 & 10,90 & 10,30 \\
\hline $01 / 2018$ & 14,90 & 13,30 & 19,20 & 19,20 & 15,70 & 13,80 & 15,00 & 12,10 & 10,40 \\
\hline $04 / 2018$ & 15,70 & 12,30 & 18,70 & 20,30 & 14,10 & 14,10 & 15,00 & 11,60 & 10,10 \\
\hline $07 / 2018$ & 14,60 & 11,60 & 18,70 & 18,20 & 13,50 & 14,40 & 14,60 & 10,20 & 10,10 \\
\hline $10 / 2018$ & 15,10 & 11,00 & 16,60 & 17,30 & 12,60 & 12,20 & 14,20 & 9,10 & 8,90 \\
\hline 01/2019 & 15,40 & 12,70 & 17,70 & 18,70 & 13,20 & 14,30 & 14,80 & 10,10 & 8,90 \\
\hline 04/2019 & 15,40 & 11,70 & 17,90 & 18,60 & 11,70 & 14,80 & 14,10 & 10,00 & 10,10 \\
\hline 07/2019 & 15,00 & 12,10 & 18,10 & 16,70 & 11,80 & 15,00 & 13,10 & 10,80 & 10,10 \\
\hline $10 / 2019$ & 13,90 & 10,60 & 15,50 & 16,40 & 11,00 & 12,40 & 12,70 & 8,30 & 8,80 \\
\hline $01 / 2020$ & 14,80 & 12,60 & 15,20 & 18,90 & 13,50 & 12,70 & 13,50 & 9,20 & 9,80 \\
\hline
\end{tabular}

Fonte: Ipeadata (disponível em: http://ipeadata.gov.br/beta3/; acesso em: 7 ago 2020).

amostrais, ele é um instrumento de baixo custo de coleta de opiniões e preferências que garante anonimato e respostas de qualidade (Weber e Bradley, 2006), além de não afetar criticamente os padrões de associações mais significativos (Heiervang e Goodman, 2011).

Nesse sentido, a análise a seguir está mais centrada no exame das relações entre insegurança econômica, medida pelo impacto da Covid-19 sobre as chances de perder rendimentos, e as características sociais dos informantes, mais especificamente seu lugar de moradia, sua cor autodeclarada, seu gênero, sua idade e sua ocupação socioprofissional. Antes de analisar essas relações, todavia, importa apresentar uma rápida descrição das variáveis que constituem a base informacional da amostra. 
No total, 2.651 questionários foram preenchidos. Destes, 168 foram descartados quer seja porque omitiam a maioria das informações solicitadas, quer seja porque provinham de pessoas que não moravam na RMRJ. Desse modo, a análise baseou-se nas informações de 2.483 questionários. A distribuição espacial dos informantes é comunicada no Quadro 2.

A Baixada Fluminense é o espaço da RMRJ com maior número de questionários preenchidos: 1.310 no total. Visto que o acesso a informações na periferia da RMRJ pode ser considerado um desafio, sobretudo em tempo de pandemia, o número de questionários coletados é expressivo. Em seguida, vêm a Zona Norte (com 391), a Zona Oeste (com 365), a Zona Sul (com 242) e o centro da cidade do
Rio de Janeiro (com 55); os demais municípios da RMJR somam apenas 120 respostas. Em função do tamanho total da amostra, assim como das principais subamostras, aquelas com informações registradas em mais de 100 questionários, podemos ficar mais confiantes que, apesar das limitações associadas à aplicação de surveys on-line, este exame do impacto inicial da Covid-19 na insegurança econômica entre os diversos espaços da RMRJ proporciona informações e conhecimentos estatísticos robustos e válidos.

No tocante à distribuição étnica/racial, a maioria dos informantes identifica-se como branca. Como pode ser observado no Quadro 3 , eles representam $52,74 \%$ da amostra. Os autodeclarados pardos são o segundo grupo

Quadro 2 - Distribuição espacial dos informantes

\begin{tabular}{|l|r|r|}
\hline & Total & $\%$ \\
\hline Zona Sul & 242 & 9.75 \\
Baixada & 1.310 & 52.76 \\
Centro & 55 & 2.22 \\
Outros & 120 & 4.83 \\
Zona Norte & 391 & 15.75 \\
Zona Oeste & 365 & 14.70 \\
\hline
\end{tabular}

Fonte: dados da pesquisa e elaboração pelos autores.

Quadro 3 - Composição da amostra por etnia/cor

\begin{tabular}{|l|r|r|}
\hline & Total & $\%$ \\
\hline Branco(a) & 1.307 & 52,74 \\
Asiático(a) & 2 & 0,08 \\
Indígena & 12 & 0,48 \\
Pardo(a) & 806 & 32,53 \\
Preto(a) & 351 & 14,16 \\
\hline
\end{tabular}

Fonte: dados da pesquisa e elaboração pelos autores. 
mais importante, com $32,53 \%$ da amostra, seguido pelos pretos, com $14,16 \%$. A amostra conta também com 2 asiáticos e 12 informantes indígenas. Cabe notar que a distribuição étnico-racial verificada no survey não é muito diferente daquela registrada pela Pesquisa Nacional por Amostra Domiciliar (Pnad) realizada pelo IBGE. Segundo a Pnad de $2015,{ }^{3}$ a composição étnica da RMRJ era de $45 \%$ de brancos, $39 \%$ de pardos e $15 \%$ de pretos.

Com 1.708 respostas, as mulheres representam mais de dois terços da amostra (Quadro 4). Essa participação diferenciada das mulheres é uma característica que afeta a maioria dos web-surveys (Busby e Yoshida, 2015). Cria um viés amostral. No entanto, dado que o número de informantes masculinos é grande - são 764 no total -, a análise da associação entre insegurança econômica e gênero permanece válida. 0 mesmo não pode ser dito no caso do gênero "outro", pois a amostra só conta com nove registros dessa categoria. Dessa forma, a análise não levará em conta os resultados envolvendo essa categoria

A composição por tipo de ocupação registrada pelo survey é outra categoria que apresenta um viés amostral significativo. Como pode ser observado no Quadro 5, o survey foi

Quadro 4 - Composição da amostra por Gênero

\begin{tabular}{|l|r|r|}
\hline & Total & $\%$ \\
\hline M & 764 & 30.79 \\
F & 1.708 & 68.84 \\
Outro & 9 & 0.36 \\
\hline
\end{tabular}

Fonte: dados da pesquisa e elaboração pelos autores.

Quadro 5 - Composição da amostra por Ocupação

\begin{tabular}{|l|r|r|}
\hline & Total & $\%$ \\
\hline Funcionário Público & 727 & 29,29 \\
Aposentado & 131 & 5,28 \\
Desempregado & 139 & 5,60 \\
Dona de casa & 64 & 2,58 \\
Empresário & 55 & 2,22 \\
Estagiário & 78 & 3,14 \\
Estudante & 251 & 10,11 \\
Freelancer/Bico & 24 & 0,97 \\
Microempreendedor & 123 & 4,96 \\
Outro & 59 & 2,38 \\
Profissional liberal & 110 & 4,43 \\
Trabalhador formal & 554 & 22,32 \\
Trabalhador informal & 167 & 6,73 \\
\hline
\end{tabular}

Fonte: dados da pesquisa e elaboração pelos autores. 
Quadro 6 - Composição da amostra por Perdas de Rendimentos

\begin{tabular}{|l|c|c|}
\hline & Total & $\%$ \\
\hline Nenhuma & 698 & 31,93 \\
Até 10\% & 140 & 6,40 \\
De 10 a 20\% & 230 & 10,52 \\
De 20 a 50\% & 548 & 25,07 \\
De 50 a 75\% & 308 & 14,09 \\
Acima de 75\% & 262 & 11,99 \\
\hline
\end{tabular}

Fonte: dados da pesquisa e elaboração pelos autores.

respondido por uma grande proporção de servidores públicos. Todavia, como observado anteriormente, pode-se considerar que esse viés não invalida os resultados da análise das associações entre perda de rendimentos e ocupação para as demais categorias de ocupação, que ainda contam com um número razoável de informantes. No exame dessas associações, é possível considerar que os subconjuntos amostrais com um número de informantes superior a cem garantem a validade da análise. Nesse sentido, os resultados da análise das relações entre perdas de rendimentos e categorias socioprofissionais, como empresários, estagiários, dona de casa ou "bicos", devem ser vistos com precaução. No entanto, pode-se confiar na validade dos demais resultados com muito mais segurança.

O Quadro 6, por fim, apresenta a distribuição das perdas de rendimentos. Percebe-se que, na segunda quinzena de abril de 2020, a pandemia já tinha afetado os rendimentos de cerca de $68 \%$ dos informantes da amostra. Mais de um quarto destes sofreu perdas iguais ou superiores a $50 \%$, e mais da metade teve seus rendimentos reduzidos acima de $20 \%$. Quem mais sofreu com esse drástico aumento da insegurança econômica? Quais foram os espaços da RMRJ em que esse aumento da insegurança econômica foi mais intenso? Procura-se, a seguir, responder a estas questões.

\section{Insegurança econômica e características socioespaciais}

A análise das relações entre insegurança econômica e características socioespaciais será feita em dois tempos. Primeiro, essas relações são verificadas separadamente por meio de uma análise de correspondência simples, uma técnica bivariada que oferece uma representação gráfica das relações entre duas variáveis categóricas (Fávero e Belfiore, 2017; Friendly e Meyer, 2015; Greenacre, 2017; Husson, Le e Pages, 2016). Em um segundo tempo, a estimação de um modelo logit para dados categóricos permitirá analisar as relações conjuntamente (Agresti, 2003; Fox, 2015). 
A representação gráfica das relações entre perdas de rendimentos e recorte espacial da RMRJ é proporcionada pelo Gráfico $1 .{ }^{4}$ Este gráfico, que é um mapa perceptual das similaridades e diferenças entre as categorias de insegurança econômica e as diferentes zonas da RMRJ, traduz, num plano bidimensional, suas relações, o que permite visualizar as similaridades e diferenças de comportamento entre as categorias.

Percebe-se, pelas coordenadas, que existem duas oposições fundamentais. Uma entre a Baixada Fluminense e a Zona Sul e outra entre segurança econômica, representada pelas coordenadas das categorias "nenhuma perda" e "até $10 \%$ ", e as perdas de rendimentos acima de $20 \%$. Observe-se também que há, por um lado, proximidade entre as coordenadas da Baixada Fluminense e as maiores perdas de rendimentos enquanto, por outro lado, há proximidade entre a Zona Sul e segurança econômica.

A análise da tabela cruzada, na qual as linhas representam as categorias de perdas de rendimentos e as colunas as categorias espaciais da RMRJ, complementa a análise gráfica. O Quadro 7 apresenta os resíduos padronizados, o valor positivo indicando uma possível associação positiva entre categorias e o valor negativo, o contrário. Nota-se que as associações mais significativas ocorrem, de um lado, entre a Zona Sul e a segurança econômica e, de outro lado, entre a Baixada Fluminense e as perdas de rendimentos acima dos $20 \%$.

Gráfico 1 - Mapa perceptual das similaridades e diferenças entre perda de renda versus zonas da RMRJ

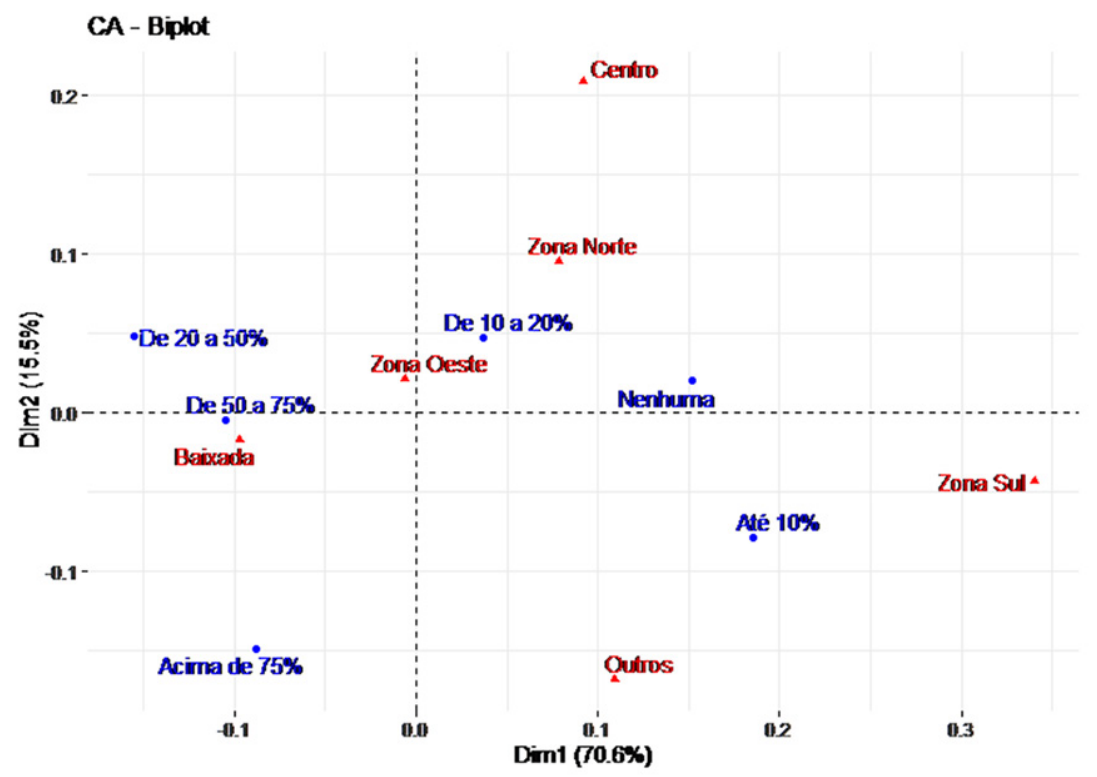

Fonte: dados da pesquisa e elaboração pelos autores. 
Quadro 7 - Resíduos padronizados da tabela cruzada perda de renda versus zonas RMRJ

\begin{tabular}{|l|c|c|c|c|c|c|}
\hline & Zona Sul & Baixada & Centro & Outros & Zona Norte & Zona Oeste \\
\hline Nenhuma & $\mathbf{3 . 3 3 1}$ & -4.196 & 0.865 & 1.453 & 2.387 & -0.535 \\
Até 10\% & $\mathbf{2 . 9 5 1}$ & -1.005 & -0.439 & -0.345 & -1.009 & 0.323 \\
De 10 a 20\% & 0.739 & -0.529 & 0.295 & -1.053 & 0.054 & 0.592 \\
De 20 a 50\% & -3.532 & $\mathbf{3 . 2 1 0}$ & -0.190 & -2.018 & -0.100 & -0.135 \\
De 50 a 75\% & -1.968 & 1.057 & 0.485 & 0.263 & -0.944 & 0.778 \\
Acima de 75\% & -0.883 & $\mathbf{1 . 8 6 5}$ & -1.455 & 1.580 & -1.573 & -0.689 \\
\hline
\end{tabular}

Fonte: dados da pesquisa e elaboração pelos autores.

Como pode ser observado, os maiores desvios entre valores esperados e os valores observados estão relacionados com essas categorias. 0 valor significativo do resíduo padronizado na relação entre as categorias "nenhuma perda" e "Zona Sul" informa que um morador da "Zona Sul" tem maior tendência a não perder nenhuma renda do que a média dos moradores da RMRJ, enquanto o valor negativo do resíduo padronizado entre as categorias "nenhuma perda" e "Baixada Fluminense" indica que os moradores desse espaço têm maior tendência a perder alguma renda do que os moradores dos demais espaços da RMRJ. Em outras palavras, os dados da pesquisa apontam para a existência de desigualdades espaciais ante o risco de perda de renda em decorrência da pandemia de Covid-19. A Zona Sul é o espaço no qual esse risco é menor, e a Baixada Fluminense é o espaço no qual esse risco é maior.
O Gráfico 2 aponta uma associação entre composição racial/étnica e perdas de rendimentos. Nesse gráfico, omitem-se os dados relativos a informantes asiáticos ou indígenas porque compõem uma subamostra demasiadamente reduzida para propocionar alguma informação confiável. Pela análise de correspondência, percebe-se que as associações mais significativas, representadas graficamente pelas categorias das variáveis de linhas e colunas que se encontram próximas umas das outras e mais longe do centro, são aquelas que vinculam "branco(a)s" com "nenhuma perda", "pardo(a)s" com perdas de "20 a 50\%" e "preto(a)s" com perdas de "até 10\%". De modo mais geral, o Gráfico 2 destaca a desigualdade racial diante das perdas de rendimentos provocadas pela pandemia, a segurança econômica de "branco(a)s" contrastando com a insegurança econômica dos demais grupos étnico-raciais. 
Gráfico 2 - Mapa perceptual das similaridades e diferenças entre perda de renda versus etnia/cor

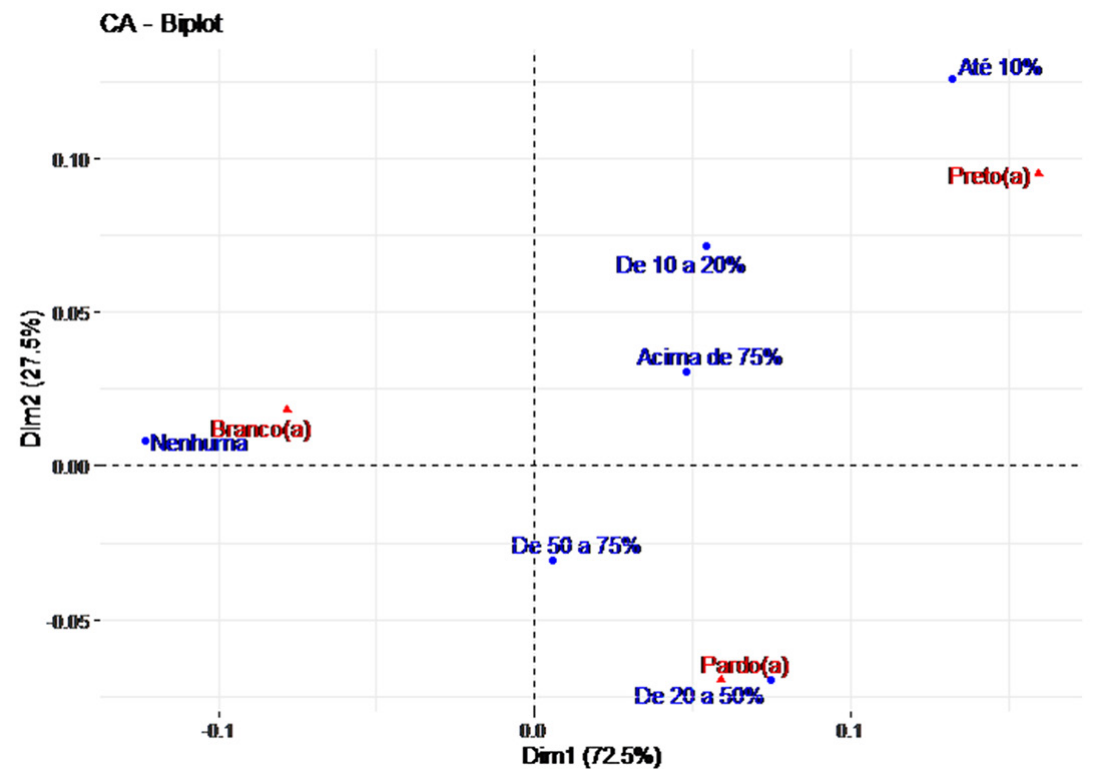

Fonte: dados da pesquisa e elaboração pelos autores.

O Quadro 8 oferece os valores dos resíduos padronizados da tabela cruzada na qual as linhas indicam as categorias de perdas de rendimentos e as colunas, por seu turno, as diferentes categorias de etnia/cor. Além das associações já mencionadas pela análise de correspondência, o Quadro 8 permite destacar mais precisamente que "preto(a)s" são o grupo étnico-racial que mais tende a sofrer algum tipo de perda de rendimentos. Nesse segmento, os valores observados distanciam-se mais negativamente dos seus valores esperados no que tange à sua segurança econômica. ${ }^{5}$

Quando se analisam as similaridades e diferenças entre categorias do tipo de ocupação profissional e de segurança econômica, é possível observar três grupos principais de associações. De um lado, a categoria "funcionário público" está relacionada com total segurança econômica, o que é de se esperar. De outro lado, entre aqueles que mais sofrem com insegurança econômica se encontram os microempreendedores individuais, os trabaIhadores informais e os profissionais liberais.

Para estes últimos, a pandemia de Covid-19 teve um impacto econômico significativo, ocasionando, na maioria dos casos, perdas de rendimentos acima de $50 \%$. A situação mais delicada é a dos microempreendedores individuais que apresentam forte associação com perdas acima de $75 \%$. Os trabalhadores formais ocupam uma posição intermediária. 
Quadro 8-Resíduos padronizados da tabela cruzada perda de renda versus etnia/Cor

\begin{tabular}{|l|c|c|c|}
\hline & Branco(a) & Pardo(a) & Preto(a \\
\hline Nenhuma & 3,774 & $-2,051$ & $-2,655$ \\
Até 10\% & $-0,966$ & $-0,611$ & 2,219 \\
De 10 a 20\% & $-0,411$ & $-0,611$ & 1,419 \\
De 20 a 50\% & $-2,548$ & 2,594 & 0,154 \\
De 50 a 75\% & $-0,305$ & 0,566 & $-0,328$ \\
Acima de 75\% & $-0,582$ & $-0,087$ & 0,955 \\
\hline
\end{tabular}

Fonte: dados da pesquisa e elaboração pelos autores.

Gráfico 3 - Mapa perceptual das similaridades e diferenças entre perda de renda versus ocupação profissional

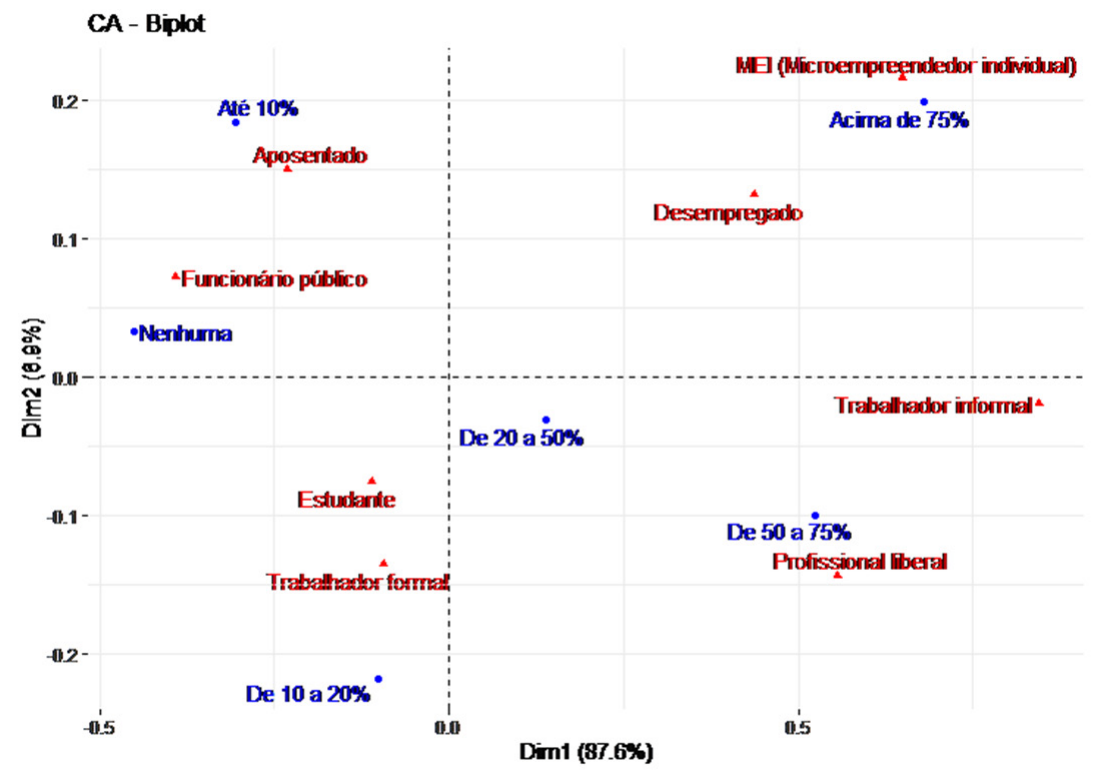

Fonte: dados da pesquisa e elaboração pelos autores. 
Os dados da pesquisa apresentam evidências de que essa categoria sofreu algum tipo de diminuição de seus rendimentos, na ordem de 10 a $20 \%$, perdas que podem, por exemplo, resultar na diminuição da carga de trabalho.

O Quadro 9 apresenta a distribuição das perdas de rendimentos segundo os genêros assim como os resíduos - entre parênteses -, ou seja, as diferenças entre valores observados e valores esperados. Os dados apontam para o fato de que as mulheres tendem a sofrer maior perda de renda do que os homens; o valor negativo dos resíduos padronizados sinalizando uma relação negativa entre o gênero feminino e uma renda $100 \%$ segura. Em especial, a pesquisa detectou signifivativa desigualdade de gênero diante dos impactos da pandemia na renda, quando essa perda é superior a $75 \%$, um aspecto que reitera a estrutural desigualdade de gênero no mercado de trabalho (Abram, 2006; Neri, 2011; Santos, 2010).

Pode-se apreender as relações entre insegurança econômica e características sociais no seu conjunto por meio de um modelo de regressão logística. Neste, a variável dependente é uma variável binária que toma o valor 1 se o informante não sofreu nenhuma perda de renda e o valor 0 em caso contrário. 0 homem branco que mora na Zona Sul serve, nesse modelo, de referência para comparar as chances dos demais perfis sociais da RMRJ, que sofreram algum tipo de perda de rendimento. Os resultados do modelo são informados no Quadro 10.

Quadro 9-Tabela cruzada perda de renda versus etnia/cor (com resíduos padronizados)

\begin{tabular}{|l|c|c|c|}
\hline & M & $\mathbf{F}$ & Outro \\
\hline Nenhuma & 223 & 474 & 1 \\
& $(1.336)$ & $(-1.144)$ & 2 \\
\hline Até 10\% & 44 & 94 & $(-1.344)$ \\
\hline De 10 a 20\% & $(0.371)$ & 168 & $(1.941)$ \\
\hline De 20 a 50\% & 61 & $(1.217)$ & 1 \\
\hline De 50 a 75\% & $(-1.229)$ & 373 & $(0.057)$ \\
\hline Acima de 75\% & 170 & $(-0.725)$ & 3 \\
& $(0.647)$ & 215 & 2 \\
\hline
\end{tabular}

Fonte: dados da pesquisa e elaboração pelos autores. 
Quadro 10 - Modelo logit para estimar as relações entre segurança econômica e variáveis socioespaciais

\begin{tabular}{|c|c|}
\hline & $\begin{array}{c}\text { Dependent variable: } \\
\text { Nenhuma Perda }\end{array}$ \\
\hline Baixada & $\begin{array}{c}-0.518^{* * *} \\
(0.157)\end{array}$ \\
\hline Centro & $\begin{array}{l}-0.073 \\
(0.349)\end{array}$ \\
\hline Outros & $\begin{array}{l}-0.145 \\
(0.244)\end{array}$ \\
\hline Zona Norte & $\begin{array}{l}-0.126 \\
(0.180)\end{array}$ \\
\hline Zona Oeste & $\begin{array}{c}-0.392 * * \\
(0.186)\end{array}$ \\
\hline Asiático(a) & $\begin{array}{c}-11.794 \\
(229.483)\end{array}$ \\
\hline Indígena & $\begin{array}{l}-0.553 \\
(0.815)\end{array}$ \\
\hline Pardo(a) & $\begin{array}{l}-0.206 * \\
(0.106)\end{array}$ \\
\hline Preto(a) & $\begin{array}{c}-0.393^{* * *} \\
(0.148)\end{array}$ \\
\hline Mulher & $\begin{array}{l}-0.133 \\
(0.100)\end{array}$ \\
\hline Gênero outro & $\begin{array}{l}-1.368 \\
(1.071)\end{array}$ \\
\hline Constant & $\begin{array}{l}-0.185 \\
(0.158)\end{array}$ \\
\hline Observations & 2,181 \\
\hline Log Likelihood & $-1,346.984$ \\
\hline Akaike Inf. Crit & $2,717.968$ \\
\hline Note & $* p^{* *} p^{* * *} p<0.01$ \\
\hline
\end{tabular}

Fonte: dados da pesquisa e elaboração pelos autores.

Percebe-se que as chances de o homem branco morador da Zona Sul manter seus rendimentos são maiores do que todos os demais habitantes da RMRJ. A segurança econômica ante a pandemia de Covid-19 tem, portanto, cor, gênero e lugar de moradia. Por exemplo, nota-se que, em comparação com os moradores da Zona Sul, os da Baixada e da Zona Oeste (exceção a moradores da Barra da Tijuca e do Recreio, que moram próximos às praias oceânicas) enfrentam situações de insegurança econômica significativamente maior. É estatisticamente significativo que eles têm probabilidades maiores de sofrer perdas de rendimentos do que aqueles que habitam a Zona Sul. Observe-se, igualmente, que pardo(a)s e, sobretudo, preto(a)s têm chances significativamente maiores do que branco(a)s de enfrentar uma diminuição de seu poder de compra em decorrência do impacto econômico da Covid-19. 
Baseada nas informações do survey, a análise dos resultados do modelo logit sugere que quem reside na Baixada Fluminense tem 1,67 vezes mais chances de sofrer alguma perda de rendimentos do que quem mora na Zona Sul. No caso da Zona Oeste estas são 1,47 superiores. Nota-se, além disso, que a insegurança econômica decorrente da pandemia aflige significativamente mais preto(a)s e pardo(a)s do que branco(a)s. Estes últimos possuem 1,48 vezes mais chances do que preto(a)s de manter seus rendimentos. Branco(a)s têm, igualmente, 1,22 mais chances de gozar de segurança econômica plena do que pardo(a)s. Os dados do survey sinalizam, ainda, que as mulheres têm 1,14 mais chances de perder rendas do que os homens. 0 resultado carece de significância estatística, mas, como mostrou o Quadro 9, elas têm mais tendência em perder acima de $75 \%$ de sua renda do que eles. Ainda que esses resultados devam ser vistos com precaução, devido aos vieses amostrais da pesquisa, eles apontam para o fato de que a desigualdade econômica ante a pandemia tem não somente um componente espacial e racial como provavelmente também um componente de gênero.

\section{Conclusão}

Apesar das limitações no tocante à representatividade amostral dos dados coletados e da impossibilidade de captar de forma mais qualitativa os impactos da pandemia nas inseguranças dos moradores da RMRJ, a análise multivariada do survey permite destacar associações válidas entre categorias socioespaciais. A análise dos dados do web-survey confirma as hipóteses apontadas na literatura internacional no que diz respeito ao papel da pandemia de Covid-19 no agravamento de desigualdades sociais preexistentes. Ao mesmo tempo, esses dados materializam espacialmente essas tendências gerais no contexto específico da desigualdade estrutural que caracteriza a Região Metropolitana do Rio de Janeiro: são os moradores dos municípios e bairros mais distantes da Zona Sul que enfrentam os transportes urbanos lotados, em tempos de pandemia, para chegarem ao local de trabalho. A segurança econômica adiante da pandemia de Covid-19 é desigual. Tem lugar de moradia, cor e gênero. 


\section{[I] https://orcid.org/0000-0003-0859-2568}

Universidade Federal Rural do Rio de Janeiro, Instituto Multidisciplinar, Programa de Pós-Graduação de Ciências Sociais em Desenvolvimento, Agricultura e Sociedade. Rio de Janeiro, RJ/Brasil.

gflexor@gmail.com

\section{[II] https://orcid.org/0000-0001-7679-4722}

Universidade Federal Rural do Rio de Janeiro, Instituto Multidisciplinar, Programa de Pós-Graduação em Desenvolvimento Territorial e Políticas Públicas; Programa de Pós-Graduação em Ciência, Tecnologia e Inovação em Agropecuária. Seropédica, RJ/Brasil.

robsondsilva@gmail.com

\section{[III] https://orcid.org/0000-0003-0594-3756}

Universidade Federal Rural do Rio de Janeiro, Instituto Multidisciplinar, Departamento de Ciências Econômicas. Nova Iguaçu, RJ/Brasil.

adriannooliveira@yahoo.com.br

\section{Nota de agradecimento}

Gostaríamos de agradecer, além dos dois pareceristas, os professores Alexandre Fortes (UFRRJ) e Álvaro Pereira do Nascimento (UFRRJ), pelos comentários e pelo generoso apoio à pesquisa.

\section{Notas}

(1) Sua criação se deu através da lei complementar federal n. 20/1974, mesma lei que instituiu a fusão dos antigos estados do Rio de Janeiro e da Guanabara.

(2) A Baixada Fluminense é constituída por 13 dos 21 municípios da RMRJ - Belford Roxo, Duque de Caxias, Guapimirim, Itaguaí, Japeri, Magé, Mesquita, Nilópolis, Nova Iguaçu, Paracambi, Queimados, São João de Meriti e Seropédica.

(3) A amostra da Pnad na RMRJ contava com as observações de 12.182 pessoas.

(4) A análise de correspondência foi realizada por meio do software R e do pacote Factominer (Lê et al., 2008)

(5) De acordo com os dados da pesquisa, "preto(a)s" têm um risco 15\% maior do que "branco(a)s" de ter alguma perda, enquanto, no caso de "pardo(a)s", esse risco é de $10 \%$. 


\section{Referências}

ABRAM, L. (2006). Desigualdades de gênero e raça no mercado de trabalho brasileiro. Ciência e Cultura, v. 58, n. 4 , pp. $40-41$.

AGRESTI, A. (2003). Categorical data analysis (Vol. 482). Canadá, John Wiley \& Sons.

BLUNDELI, R.; COSTA DIAS, M.; JOYCE, R.; XU, X. (2020). COVID-19 and Inequalities. Fiscal Studies, v. 41, n. 2, pp. 291-319.

BRITTO, A. L. et al. (2020). A pandemia de COVID-19 na RMRJ: impactos e desafios em uma ordem urbana marcada por desigualdades e vulnerabilidades socioespaciais. Disponível em: https:// www.observatoriodasmetropoles.net.br/wp-content/uploads/2020/07/Dossi\%C3\%AAN\%C3\%BAcleo-Rio-de-Janeiro_An\%C3\%A1lise-Local_Julho-2020.pdf. Acesso em: 7 ago 2020.

BUSBY, D. M.; YOSHIDA, K. (2015). Challenges with online research for couples and families: evaluating nonrespondents and the differential impact of incentives. Journal of Child and Family Studies, v. 24, n. 2 , pp. 505-513.

CÂMARA METROPOLITANA (2016). Plano Estratégico de Desenvolvimento Urbano Integrado da Região Metropolitana do Rio de Janeiro. Disponível em: https://www.modelarametropole.com.br/rmrj/.f. Acesso em: 7 ago 2020.

FÁVERO, L. P.; BELFIORE, P. (2017). Análise de dados: técnicas multivariadas exploratórias com SPSS e Stata. Rio de Janeiro, Elsevier Brasil.

FMI - International Monetary Fund (2020). World Economic Outlook. International Monetary Fund.

FOX, J. (2015). Applied regression analysis and generalized linear models. Califórnia, Sage Publications.

FRIENDLY, M.; MEYER, D. (2015). Discrete data analysis with R: visualization and modeling techniques for categorical and count data (v. 120). Flórida, CRC Press.

GREENACRE, M. (2017). Correspondence analysis in practice. Flórida, CRC press.

HEIERVANG, E.; GOODMAN, R. (2011). Advantages and limitations of web-based surveys: evidence from a child mental health survey. Social Psychiatry and Psychiatric Epidemiology, v. 46, n. 1, pp. 69-76. Disponível em: https://doi.org/10.1007/s00127-009-0171-9.

HUSSON, F.; LE, S.; PAGES, J. (2016). Analyse de données avec R. Bretanha/França, Presses Universitaires de Rennes.

LÊ, S.; JOSSE, J.; HUSSON, F. (2008). FactoMineR: an R package for multivariate analysis. Journal of Statistical Software, v. 25, n. 1, pp. 1-18.

MILANOVIC, B. (2016). Global inequality: A new approach for the age of globalization. Cambridge, Harvard University Press.

MODELAR A METRÓPOLE (2017). Disponível em: https://www.modelarametropole.com.br/wpcontent/uploads/2017/03/06-economia_-renda.jpg. Acesso em: 7 ago 2020.

NEIDHÖFER, G. (2020). Long run consequences of the COVID-19 pandemic on social inequality. Disponível em: https://www.latinamerica.undp.org/content/rblac/en/home/blog/2020/consecuencias-dela-pandemia-del-covid-19-en-las-desigualdades-s.html. 
NERI, M. (2011). Income Inequality on the Decade in Brazil. Evolution of Social Indicators Based on Income Working Paper. Rio de Janeiro, FGV/CPS.

NYQVIST, M. B. et al. (2020). COVID-19 amplifies inequality. Fight back with long-term thinking. World Economic Forum. Disponível em: https://www.weforum.org/agenda/2020/07/covid-19amplifies-inequality-fight-back-with-long-term-thinking/.

OSORIO, M.; VERSIANI, M. H.; ERTHAL, L.; FREITAS, A.; FILHO, M. A.; SOBRAL, B.; SANCHES, I.; CABRAL, J.; MONTIBElER, E.; CABRAL, M. V. (2020). A crise no Estado do Rio de Janeiro. Jornal dos Economistas. Rio de Janeiro, Corecon-RJ e Sindecon-RJ, n. 371 Julho de 2020. Disponível em https://www.corecon-rj.org.br/anexos/85F36ADF55DC9B4E4C5A7458B5F007F7.pdf. Acesso em: 20 ago 2020 .

PIKETTY, T. (2014). O capital no século XXI. São Paulo, Intrínseca.

PNAD-COVID19. Disponível em: https://covid19.ibge.gov.br/pnad-covid/. Acesso em: 7 ago 2020.

SANTOS, J. A. F. (2009). Structural interaction between gender and race inequality in Brazil. Revista Brasileira de Ciências Sociais, v. 24, n. 70, pp. 37-60.

WEBER, J. A.; BRADLEY, K. D. (2006). Strengths and weaknesses of conducting web-based surveys: A review of the literature. Mid-Western Educational Research Association Annual Meeting. Disponível em: http://www.uky.edu/ kdbrad2/Web-basedSurveys.pdf. Acesso em: 7 ago 2020.

Texto recebido em $2 /$ set/2020

Texto aprovado em 15/jan/2021 